\title{
Factors Influencing Knowledge and Attitude of Mothers Towards Immunization of Children Under-Five Years in Farato, Gambia
}

\author{
Lamin Kanyi \\ Department of Public Health, Zambia Campus, Lusaka
}

\begin{abstract}
Globally, immunization coverage dropped from $86 \%$ in 2019 to $83 \%$ in 2020. An estimated 23 million children under one year did not receive basic vaccines, which is the highest number since 2009. Thus, this study aimed at identifying factors influencing the knowledge and attitude of mothers of under-five children towards immunization in Farato, The Gambia. A descriptive cross-sectional study was conducted in the peri-urban community of Farato. A sample of 132 mothers were conveniently sampled and interviewed using a structured questionnaire. Descriptive statistics such as percentages, frequencies, and proportions were used to present the results of this study. The study revealed a low level of knowledge of mothers towards immunization. About 25\% of mothers cannot clearly explain immunization; $23 \%$ knew that the first vaccine dose should be administered to a child at birth or soon after, and 60\% were found to be unaware if their children were immunized. This indicates that the concept of immunization is not even clear to mothers and also showcased inadequate knowledge. However, $70 \%$ highlighted that immunization prevents infections and enhances child survival. Inadequate knowledge about immunization, literacy and education level, occupation of mothers, inadequate information from health workers, and limited information among mothers were major influencing factors to drop-out of immunization uptake. The study suggests that mothers need to be taught what immunization is about and its importance to children. At health facilities and clinic sites, health workers need to continue communicating to mothers on the importance of immunization to enlighten them about immunization.
\end{abstract}

Keywords: Attitude, Farato, Influencing factors, Knowledge, Mothers, and children under five years.

\section{Introduction}

Globally, immunization coverage dropped from $86 \%$ in 2019 to $83 \%$ in 2020 [1]. An estimated 23 million children under one year did not receive basic vaccines, which is the highest number since 2009 [1]. In 2020, the number of completely unvaccinated children increased by 3.4 million [1, 2]. In Africa, for every additional COVID-19 deaths as a result of SARS-CoV-2 infections acquired during child vaccination visits, 84 deaths could be averted through sustained childhood vaccination program [3]. Thus, there is an increase benefit-risk ratio for households with vaccinated children in Africa [3]. High routine immunization coverage epitomizes disease prevention, outbreaks control, and enhanced child survival and development, thus averting 4 million deaths every year [4]. Achieving this has remained a huge challenge in many underdeveloped and developing nations especially in Africa thus, resulting in rising cases of vaccinepreventable diseases (VPDs); 30 million children under five years still suffer from vaccine-preventable diseases every year in Africa [5, 6]. Parental decisions about vaccinations for their children fall into several kinds. They range from outright refusal of all immunizations, premeditated delay, or selective absence, to complete compliance with the comprehensive vaccination schedule [7]. To 
accomplish high immunization coverage of above $90 \%$, understanding the importance of immunization and positive attitudes of care seekers, especially mothers with children less than five years, is critical in ensuring that the desired coverage are attained. This is not the case in most parts of Africa, as immunization coverage has stagnated in many countries. The African Region still lags behind other regions of the world in access to vaccines [4]. A low level of awareness on vaccines culminates in misconceptions resulting in gross vaccine hesitancy and or refusal [8]. This has seriously undermined countries efforts to increase immunization performance to seize the chain of transmission of vaccine-preventable diseases [9].

Immunization coverage was 77 percent in the WHO-AFRO region in 2014 , with a 90 percent prevalence at the state level in up to 18 countries [10]. However, immunization coverage has stayed at $72 \%$ in Sub-Saharan Africa for the last five years, while almost 31 million children under the age of five die each year from vaccine-preventable diseases [11]. Numerous immunization programs have advanced in underdeveloped nations, although the prevalence in some places remains stagnant. A significant number of children do not finish their immunization schedules due to a variety of causes, including mothers/caregivers, limitations, and other confounding variables [12]. Mothers have a high level of awareness and favorable attitudes toward childhood immunization, according to studies [13-15]. However, a study published in 2019 [16] reported that mothers lacked knowledge and attitudes toward immunization exercises and found no significant correlation between demographic and socioeconomic factors and attitudes toward these activities. Sarfaraz et al. 2017 found a substantial difference in mothers' knowledge, attitude, and perspective of child health from 2-4 in pre-intervention to 10-12 in post-intervention [17]. Inadequate vaccine services and caregiver mobility have resulted in children receiving insufficient vaccination [18]. Additionally, the mother's level of education, household income level, and walking distance to clinic facilities contributed to coverage gaps $[15,19]$.

The government of The Gambia has made several efforts to improve child health care at large. A recent study in the rural Gambia revealed that childhood vaccination uptake to achieve all the required doses was 66\% [20]. At the same time, antigen-specific coverages were remarkably different across vaccines such as BCG, Polio, Penta 3, Measles-rubella, and yellow fever. Both caregivers/mother's level of awareness, mothers/caregiver's occupation, family size, and occupation of child's father were determinants of vaccination coverage for children in rural Gambia [15, 20]. Despite these efforts, there is still a problem where mothers do not have enough knowledge and awareness to help them understand immunization [4]. Since the Gambia register its first COVID-19 case in March 16, 2020, childhood immunization coverage became a very sensitive issues especially in rural settings [21]. Generally, no study in the Gambia has been conducted to assess the factors leading to the poor attitude of mothers towards immunization.

Thus, this study aims to identify factors influencing the knowledge and attitude of mothers of under-five children towards immunization in Farato. Specific study objectives were to determine the present immunization status of under-five children; to assess the current level of knowledge and attitude of mothers of under-five and its influence on their immunization. This study is among the foremost studies that had looked explicitly into mother's or caregiver's awareness of their under-five immunization status in the Gambia.

\section{Materials and Methods}

A descriptive community-based crosssectional study design was used to conduct this study in peri-urban community of Farato. 
Quantitative data was collected from mothers of children under-five years. Mothers were without their children's Infant Welfare Card were excluded from the study.

\section{Sample Size Determination and Selection}

The study sample size was calculated using the Cochrane formula as shown below:

$$
N=\frac{Z P(1-P)}{E}
$$

Where:

$$
\begin{aligned}
& \mathrm{N}= \text { Sample size. } \\
& \mathrm{P}= \text { The proportion of mothers who are } \\
& \text { aware and have knowledge on } \\
& \text { childhood immunization which is } \\
& 10 \% . \\
& \mathrm{E}= \text { Maximum error of the study, which } \\
& \text { is } 0.05 . \\
& \mathrm{Z}= \begin{array}{l}
\text { Standard normal deviation that } \\
\text { corresponds to } 5 \% \text { level of } \\
\text { statistical significance i.e:1.96. }
\end{array} \\
& \mathrm{N}=\frac{1.962 \times 0.1(1-0.1)}{0.052}
\end{aligned}
$$

Thus, N=132.4.

Therefore, the sample size for this study was 132 participants. A convenient sampling technique was used to select mothers for this study. It was done across each of the wards in the community of Farato, Kombo South District, West Coast Region of The Gambia.

\section{Data Collection Tools}

A structured questionnaire was designed, pre-tested, and validated prior to the actual data collection phase of the study. The tool was written in English Language and translated into the local languages that is most convenient for the mothers by the research assistants. All interviews were conducted in local languages such as Mandinka, Fula, and Wolof. Before the commencement of data collection, the translated tool was pretested on maternal mothers in another community within Kombo South District. Reliability was determined through the computation of Cronbach's Alpha test at 0.81 . The interviews lasted for 10 to 20 minutes. Each administered questionnaire was immediately crosschecked for completeness, accuracy, content clarity and comprehensiveness throughout the interview processes.

\section{Data Analysis}

The data were analyzed using SPSS version 25.0. A univariate analysis such as descriptive statistics were presented in frequency and percentage to explore the study variables explicitly. Cross-tabulation was also done to understand the nexus between outcome and independent variables.

\section{Ethical Consideration}

An ethical clearance was sought from the relevant Institutional Review Boards prior to the implementation of the study. Furthermore, permission was also granted from the Regional Health Directorate and the village Alkalo. At the village level, heads of households were informed of the study, and each study participant had to sign or thumbprint the consent form prior to their participation. Women were recruited voluntarily and reserved the right to stop or withdraw from the study at any stage.

\section{Results}

The findings revealed that there exists an inadequate knowledge of mothers on immunization in Farato. $25 \%$ of mothers interviewed cannot clearly explain immunization. Only 23\% knew that the first vaccine dose should be administered at birth or soon after. Likewise, $30 \%$ of the respondents said a child should be vaccinated twice to be fully protected. $67 \%$ cannot recall the age at which their child received the measles vaccine. Also, $60 \%$ said they had not immunized their child even though they were immunized and recorded on clinic cards, and 50\% of the respondents were unable to mention any of the vaccine-preventable diseases (VPDs). This indicates inadequate knowledge on 
immunization, and it also shows that the concept of immunization is not fully understood. However, $70 \%$ highlighted that immunization prevents diseases and enhances child survival.

The findings in Figure 1 shows the respondents' age groups, from 18 - 25 and $26-$ 35 years, both at $25 \%$, while the highest was $35-45$ years at $50 \%$. It is always important to make sure that we know the age groups to see the number of mothers who have more knowledge about immunizations. The study revealed that mothers who were married $(66 \%)$ had $2-3$ children, separated mothers were $33 \%$, and they all had one child each, while those that were divorced mothers were $33 \%$, and they all had $3+$ children, as shown in Table 1 . The findings have shown that mothers with 2-3 children or more failed to attend clinics routinely.

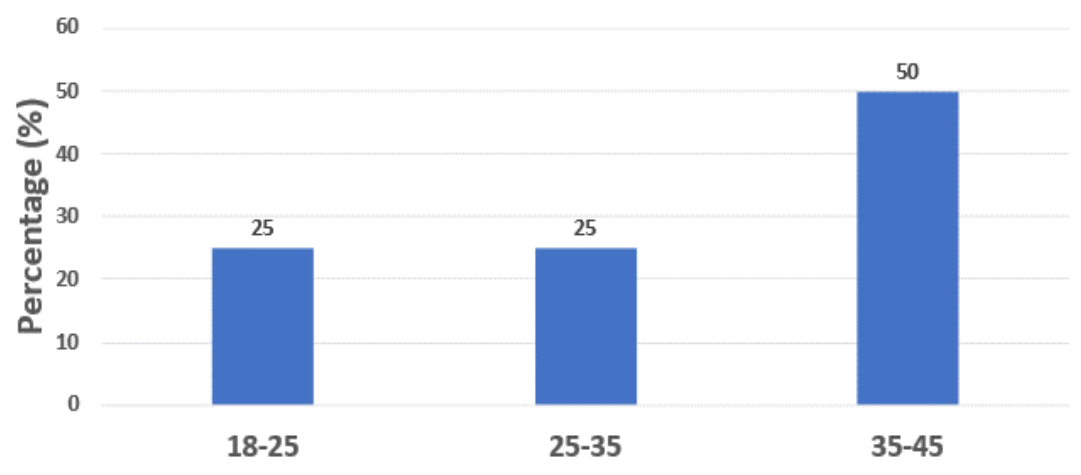

Age Distribution of respondents

Figure 1. Age Distribution of the Respondents

Table 1. Number of Children vs Marital Status Cross Tabulation

\begin{tabular}{|l|l|l|l|}
\hline \multirow{2}{*}{ Number of children } & \multicolumn{3}{|l|}{ Marital Status } \\
\cline { 2 - 4 } & Married & Separated & Divorced \\
\hline 1 & 0 & 33 & 0 \\
\hline $2-3$ & 66 & 0 & 0 \\
\hline $3+$ & 0 & 0 & 33 \\
\hline Total & 66 & 33 & 33 \\
\hline
\end{tabular}

A cross-tabulation of occupation and level of education was illustrated in Table 2. According to the respondents, it was recorded that $66 \%$ were housewives who mostly stay at home to look after household activities. They do not give much attention to immunization, limiting their knowledge on the concept of immunization. Only $10 \%$ were reported to civil servants, while about $36 \%$ of these mothers were casual employees with relatively no formal education. In terms of their understanding on the concept of immunization, $25 \%$ reported the concept to just taking children to the clinic/hospital, while the remaining $75 \%$ revealed that it is the vaccination of the children, as shown in Figure 2. Furthermore, only one-fifth (20\%) understand that immunization helps the children to grow healthy, and $80 \%$ asserted that it protects children against infections, as indicated in Figure 3. 
Table 2. Occupation and Level of Education Cross-tabulation

\begin{tabular}{|l|l|l|l|}
\hline \multirow{2}{*}{ Occupation } & \multicolumn{2}{|l|}{ Level of education } & \multirow{2}{*}{ Total } \\
\cline { 2 - 4 } & No formal education & Secondary & \\
\hline Housewife & 66 & 0 & 66 \\
\hline Civil servant & 0 & 10 & 10 \\
\hline Casual employee & 33 & 23 & 56 \\
\hline Total & 99 & 33 & 132 \\
\hline
\end{tabular}

\section{Taking kids to health center to receive}

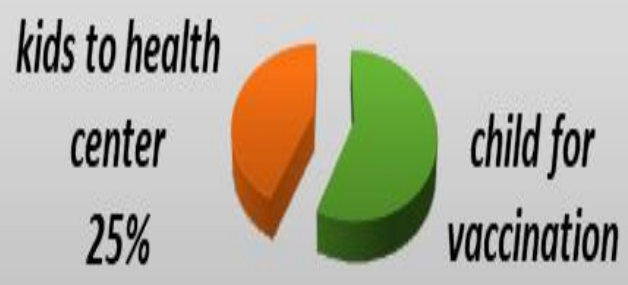

$75 \%$

Figure 2. What is Immunization

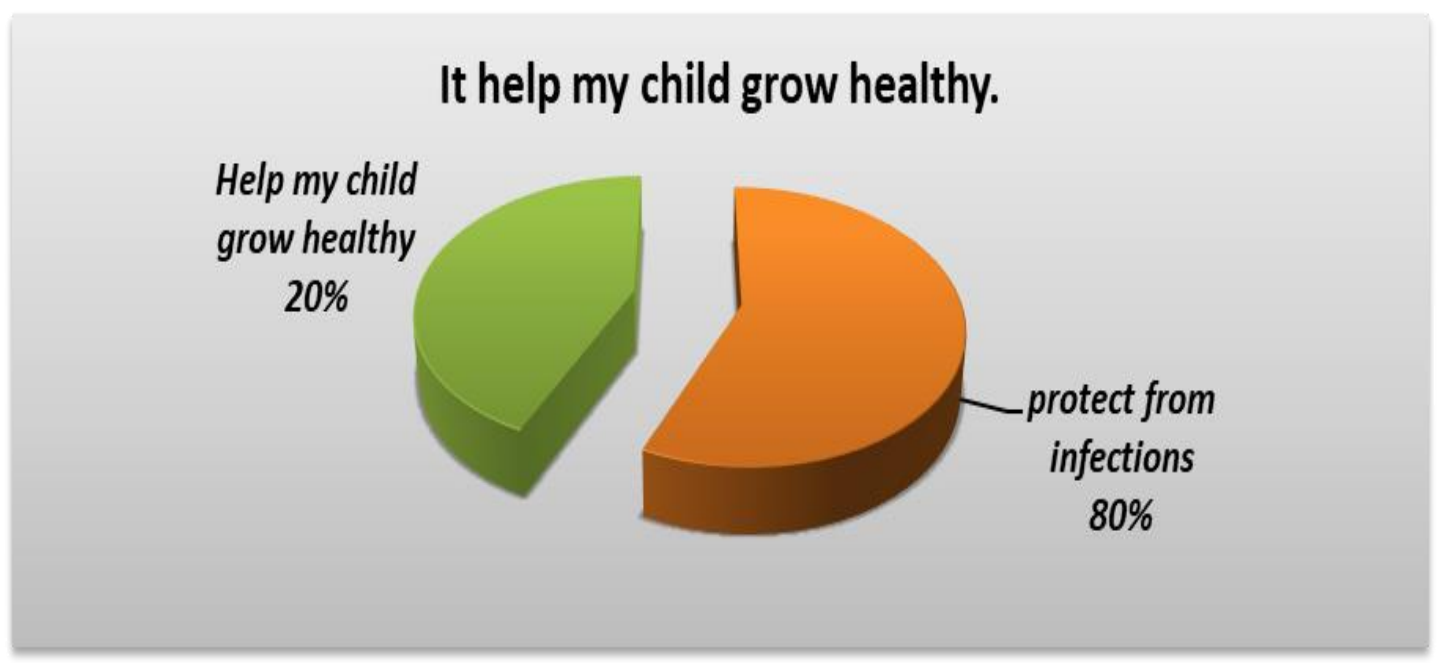

Figure 3. Reasons for Child Immunization

Mothers' knowledge on specific VPDs were also examined, as showed in Table 3. The results revealed that $33 \%$ mentioned Malaria, pneumonia, headache, and diarrhoea as VPD while another $33 \%$ reported polio, measles, and yellow fever as VPD. Of these, 23\% reported first vaccination should be received at birth, $26 \%$ reported to be at 6 weeks, while some proportion reported at six months and one year, as shown in Figure 4. Regarding mothers' opinion on the number of times a child should be vaccinated, $30 \%$ reported twice while $70 \%$ reported more than four times in order to be protected against VPDs, as illustrated in Figure 5. According to the findings, it revealed that $60 \%$ had not immunized their children. 
Interestingly, $82 \%$ of children were confirmed to be vaccinated through the child's immunization card, as shown in Figure 6. At the same time, $40 \%$ reported to have immunized their children before, which was ascertained. This indicates that $40 \%$ of mothers have some knowledge and understand child immunization.

Table 3. Knowing about Vaccine-Preventable Diseases by Types' Cross-tabulation?

\begin{tabular}{|l|l|l|l|l|}
\hline \multirow{2}{*}{$\begin{array}{l}\text { Do you know the } \\
\text { immunizable diseases }\end{array}$} & \multicolumn{2}{|l|}{ vaccine-preventable diseases } & \multirow{2}{*}{ Total } \\
\cline { 2 - 5 } & Missing & $\begin{array}{l}\text { Malaria, Pneumonia, } \\
\text { Headache \& Diarrhoea }\end{array}$ & $\begin{array}{l}\text { Polio, Measles } \\
\text { \& Yellow fever }\end{array}$ & \\
\hline Yes & 0 & 33 & 33 & 66 \\
\hline No & 66 & 0 & 0 & 66 \\
\hline Total & 66 & 33 & 33 & 132 \\
\hline
\end{tabular}

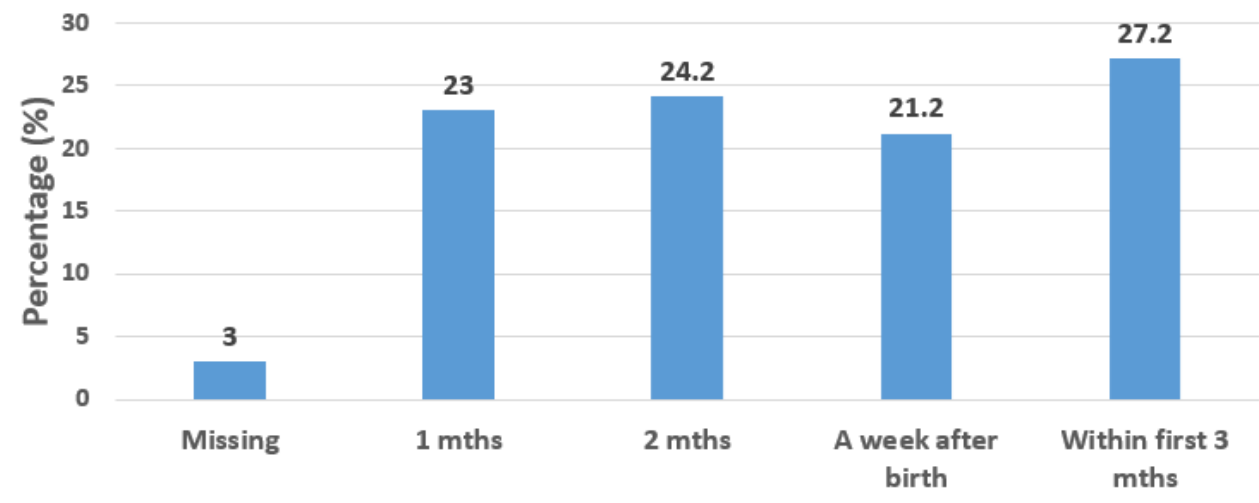

Age at which a child receive first Vaccination

Figure 4. When should a Child Get the First Vaccine?

\section{Number of times the child should be immunized}

Twice

Figure 5. How many Times should a Child be Immunized? 


\section{Have you ever immunized your child}

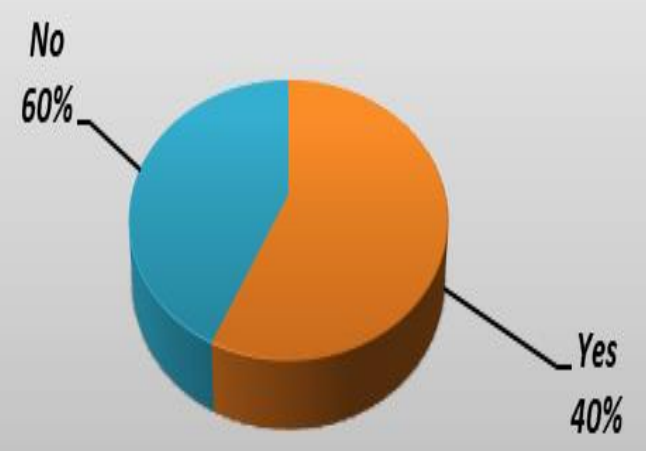

Figure 6. Have you ever Immunized your Child?

As shown in Figure 7, about $23 \%$ of the mothers reported that their children should start immunization at one month, $24.2 \%$ reported two months, $21.2 \%$ reported a week after birth, while $27.2 \%$ said within 1 to 3 months. Furthermore, mothers failing to know these will influence their decision to start immunization on time. As shown in Figure 8, about 30\% reported that their child receives measles vaccines within 1 year 9 months, while $67 \%$ could not recall if their child receives measles dose. This information is very important to mothers as it helps them know whether their children are fully immunized. It is also helpful during measles vaccination campaigns to know which children are eligible.

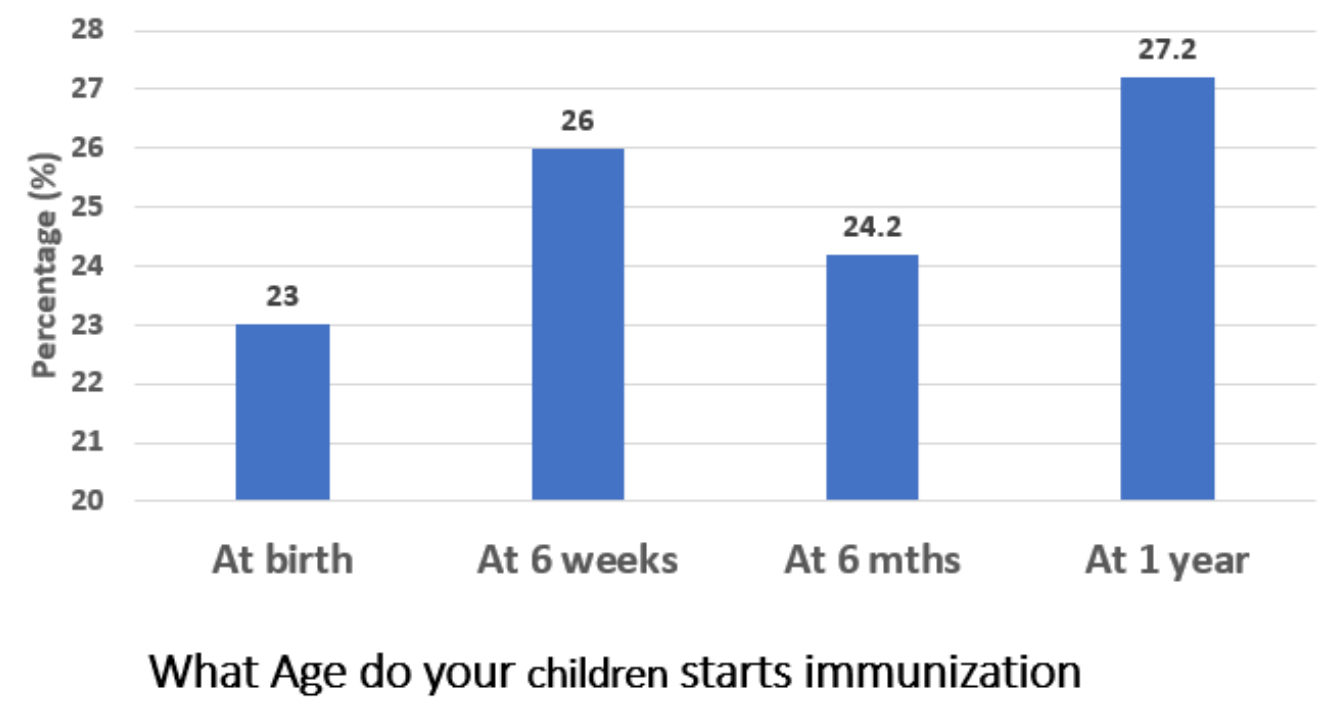

Figure 7. What ages do your Children Start Immunization? 


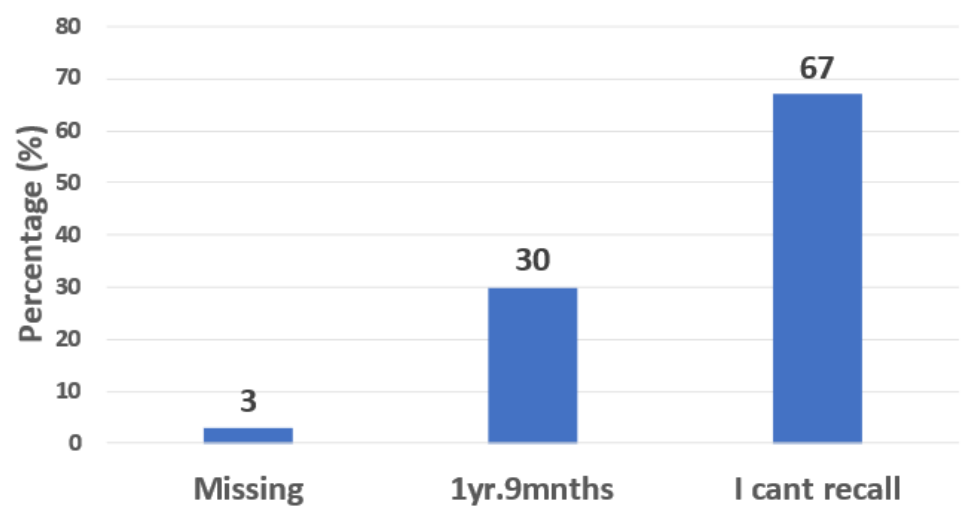

At what age did a child receive measles vaccination

Figure 8. At what age did your Children Receive the Measles Vaccine

\section{Discussion}

During the study on factors influencing the knowledge and attitude of mothers of underfive children towards immunization in Farato, so many aspects were considered. A sample size of one hundred and thirty-two (132) mothers were interviewed for a period of two (2) weeks. From the data collected, 33 mothers representing $(25 \%)$ could not explain what immunization is. Sixty-six (66) respondents, which represents $(50 \%)$ cannot mention a single vaccine-preventable disease, and 33 (43.6\%) referred to Diarrhoea, Pneumonia, and Malaria as EPI-targeted diseases. Indeed, this is quite in agreement with the study conducted in Congo; virtually all mothers have heard of immunization (99.8\%). There was, however, confusion in their minds as to which diseases are targeted by EPI. Some mothers cited Diarrhoea (3.9\%) and Malaria (3\%) as EPItargeted diseases. Most mothers attended immunization sessions without knowing exactly which vaccines they are there and which diseases they are protecting their children against [22]. Also, 26\%, 24.2\%, and 27.2\% said a child should receive the first vaccine dose at 6 weeks, six months, and one year, respectively. Thus, indicating that there is limited knowledge about immunization could dictate the attitudes and practice of mothers in seeking immunization services. The influencing factors deduced from the findings were inadequate knowledge of mothers on immunization processes, literacy and educational level of mothers, inadequate information from health workers during visits to health centers, occupation of mothers, and limited information among mothers was a major drop-out of immunization uptake [23-25].

The findings also revealed that $25 \%$ of mothers said immunization takes kids to a health center, while $75 \%$ stated that immunization takes children for vaccination to protect against diseases. Of the mothers interviewed, 50\% said they do not know VPDs, $43 \%$ misunderstood what VPDs are, and only 53 mothers knew what immunizable diseases are and could mention these diseases. Similar research conducted in southern Nigeria to assess mothers' knowledge on vaccinepreventable diseases shows that $41.3 \%$ of mothers believe that immunization can prevent Malaria (72.3\%), and $84.65 \%$ said it prevents Diarrhoea [26]. These results show knowledge gaps among respondents on the concept of immunization and vaccine-preventable diseases (VPDs). 
Also, only $23 \%$ of mothers responded that a child should receive the first vaccine dose at birth, 26\% said at 6 weeks, $24.2 \%$ said at 6 months, and the majority of the respondents (27.2\%) said a child should receive the first vaccine dose at one year of age. These findings justify the need to intensify efforts on health education and community engagement activities targeting mothers and other caregivers to raise awareness on immunization.

Likewise, $30 \%$ of the respondents said a child should be immunized twice to be protected, while $70 \%$ said a child should be immunized more than four times to attained full immunization status. Moreover, most respondents $(67 \%)$ cannot recall the age at which their child received the measles vaccine. A similar cross-sectional survey conducted by [27] among migrant mothers using a questionnaire showed high knowledge about immunization among migrant mothers with fully immunized children. These mothers were familiar with immunization from the health talks they had received on their entrance. Mother's age, education level and the number of children in the household, latest continuous living time, and monthly household income per capita was significantly associated with the immunization KAP among migrant mothers [27]. Compared to my study, the household per capita income is low as $50 \%$ of the respondents are housewives who had no formal education. Consequently, access to media by these mothers and an opportunity to benefit from health education sessions are limited; hence $30 \%$ of the respondents did not know the number of times their child should be immunized to attain fully immunized status.

In addition, my study findings have indicated that mothers in Farato delayed immunizing their children as $21.2 \%$ of mothers said they start immunizing their child a week after birth, $23 \%$ at age 1 month, $24.2 \%$ at 2, and $27.2 \%$ at 3 months. The act of mothers delaying in commencing immunization for their children has implications in attaining fully immunized status. These mothers are preoccupied with domestic work and do not prioritize immunization clinics. Hence, they do not often benefit from the pre-clinic health talks conducted at clinics to enhance their knowledge of immunization services. The MICS study conducted by the government of The Gambia and partners in 2019-20 has validated my results as $84.6 \%$ of children were fully immunized nationally [28]. Also, completing the immunization schedule and achievement of the United Nations target of $90 \%$ of children under 1 year remains a challenge even in The Gambia [29, 30].

\section{Conclusion}

The study was carried out to identify factors influencing the knowledge and attitude of mothers towards under-five children immunization in Farato, The Gambia. This is a study of selected mothers. The sample size was 132 selected mothers; this was done through a convenient sampling method. The study findings revealed that there is less knowledge about immunization from the mothers because not all mothers understand the immunization process. The study results further suggested that mothers need to be taught what immunization is all about and the importance of it towards enhancing child survival and development. At health centers/facilities and outreach immunization clinic sites, health workers need to continue communicating to mothers the importance of this program; at least $90 \%$ of mothers should know the immunization process.

\section{Conflict of Interest}

The financial implications and time required could not permit the researcher to draw samples from the West Coast Region or the entire country. Thus, the results obtained showcased the findings from Farato, where the study was limited to. The findings are not representative of the whole West Coast Region neither the entire country. 


\section{Acknowledgments}

I thank the Almighty God for His guidance and providence, which enabled me to undertake this challenging project in terms of time and resources. I acknowledge my supervisors, Dr.

\section{References}

[1] World Health Organization (2021) Fact sheets: Immunization coverage. https://www.who.int/newsroom/fact-sheets/detail/immunization-coverage.

Accessed 7 Oct 2021.

[2] UNICEF (2021) Vaccination and Immunization Statistics. In: UNICEF Data https://data.unicef.org/topic/childhealth/immunization/Accessed 8 Oct 2021.

[3] Abbas K, Procter SR, van Zandvoort K, et al (2020) Routine childhood immunisation during the COVID-19 pandemic in Africa: a benefit-risk analysis of health benefits versus excess risk of SARS-CoV-2 infection. Lancet Glob Health 8: e1264-e1272.

[4] World Health Organization (2020) Immunization. In: WHO Reg. Off. Afr. https://www.afro.who.int/health-

topics/immunization/Accessed 7 Oct 2021.

[5] World Health Organization (2018) Business case for WHO immunization activities on the African continent 2018-2030. In: WHO Reg. Off. Afr. https://www.afro.who.int/publications/businesscase-who-immunization-activities-african-continent2018-2030/Accessed 7 Oct 2021.

[6] Shah MP, Tate JE, Mwenda JM, Steele AD, Parashar UD (2017) Estimated reductions in hospitalizations and deaths from childhood diarrhea following implementation of rotavirus vaccination in Africa. Expert Rev Vaccines 16:987-995.

[7] Larson HJ, Jarrett C, Eckersberger E, Smith DMD, Paterson P (2014) Understanding vaccine hesitancy around vaccines and vaccination from a global perspective: A systematic review of published literature, 2007-2012. Vaccine 32:2150-2159.

[8] McClure CC, Cataldi JR, O'Leary ST (2017) Vaccine Hesitancy: Where We Are and Where We Are Going. Clin Ther 39:1550-1562.
Sheriffo Jagne and Dr. Lawson Simapuka, for their guidance and wise advice during the development of this project. I am grateful to my friends and family for their continued support.

[9] Piot P, Larson HJ, O'Brien KL, N'kengasong J, Ng E, Sow S, Kampmann B (2019) Immunization: vital progress, unfinished agenda. Nature 575:119129.

[10] Immunization in Africa. In: Ministry. Conf. Immun.

Afr. http://immunizationinafrica2016.org/immunizationin-africa/Accessed 7 Jul 2020.

[11]Experts caution against the stagnation of immunization coverage in Africa. In: WHO Reg. Off. Afr. https://www.afro.who.int/news/expertscaution-against-stagnation-immunization-coverageafrica/Accessed 6 Jul 2020.

[12] Taiwo L, Idris S, Abubakar A, Nguku P, Nsubuga P, Gidado S, Okeke L, Emiasegen S, Waziri E (2017) Factors affecting access to information on routine immunization among mothers of under 5 children in Kaduna State Nigeria, 2015. Pan Afr Med J. https://doi.org/10.11604/pamj.2017.27.186.11191.

[13] Kg E, Ro E (2018) Perception of Childhood Immunization among Mothers of Under-Five Children in Onitsha, Anambra State. 6:6.

[14] Adisa O, Akinleye Ca, Obafisile C, Oke O (2016) Childhood immunization perception and uptake among mothers of under-five children attending immunization clinics in Osogbo, Southwestern, Nigeria. Res J Health Sci 4:186.

[15] Kyprianidou M, Tzira E, Galanis P, Giannakou $\mathrm{K}$ (2021) Knowledge of mothers regarding children's vaccinations in Cyprus: A cross-sectional study. Plos One 16: e0257590.

[16] Hassan MR, Azman MA, Yong CL, Nazmi TMT, Rashid NNA, Azmi WNASW, Safian N, Hajib N, Al-Abed AAAA, Ghazi HF (2019) Knowledge and perception towards supplementary immunization activities (SIA) among mothers in Cheras, Kuala Lumpur. Malays J Public Health Med 19:126-131. 
[17] Sarfaraz M, Athira A, Lakshmi L, Ravilla S, Nadikudi N, Doddayya H (2017) Assessment of Knowledge, Attitude and Perception Among Mothers Towards Immunization in a Tertiary Care Teaching Hospital. Int J Community Med Public Health 4:3429-3435.

[18] Negussie A, Kassahun W, Assegid S, Hagan AK (2015) Factors associated with incomplete childhood immunization in Arbegona district, southern Ethiopia: a case-control study. BMC Public Health 16:27.

[19]Ekouevi DK, Gbeasor-Komlanvi FA, Yaya I, Zida-Compaore WI, Boko A, Sewu E, Lacle A, Ndibu N, Toke Y, Landoh DE (2018) Incomplete immunization among children aged 12-23 months in Togo: a multilevel analysis of individual and contextual factors. BMC Public Health 18:952.

[20] Touray E, Barrow A, Kinteh B, Badjie M, Nget M, Touray J, Kinteh SLS, Jatta SPS, Ceesay L (2021) Childhood vaccination uptake and associated factors among children 12-23 months in rural settings of the Gambia: a community-based crosssectional study. BMC Public Health 21:1740.

[21] Abatan B, Agboghoroma O, Akemoke F, et al (2021) Intense and Mild First Epidemic Wave of Coronavirus Disease, The Gambia. Emerg Infect Dis 27:2064-2072.

[22] Mapatano M, Kayembe K, Piripiri L, Nyandwe $\mathrm{K}$ (2008) Immunisation-related knowledge, attitudes, and practices of mothers in Kinshasa, Democratic Republic of the Congo. South Afr Fam Pract 50:61-61e.

[23] Almutairi WM, Alsharif F, Khamis F, Sallam LA, Sharif L, Alsufyani A, Alshulah FN, Alqasimi R (2021) Assessment of Mothers' Knowledge, Attitudes, and Practices Regarding Childhood Vaccination during the First Five Years of Life in Saudi Arabia. Nurs Rep 11:506-516.
[24] Saso A, Skirrow H, Kampmann B (2020) Impact of COVID-19 on Immunization Services for Maternal and Infant Vaccines: Results of a Survey Conducted by Imprint-The Immunising Pregnant Women and Infants Network. Vaccines 8:556.

[25]Bell S, Clarke R, Paterson P, Mounier-Jack S (2020) Parents' and guardians' views and experiences of accessing routine childhood vaccinations during the coronavirus (COVID-19) pandemic: A mixed-methods study in England. Plos One 15: e0244049.

[26] Uwaibi NE, Akhimienho IK (2020) Assessment of knowledge and practice of childhood routine immunization among mothers/caregivers attending primary health care centres in Benin City, Edo State, Nigeria. J Appl Sci Environ Manag 24:1703-1710. [27] Hu Y, Luo S, Lou L, Zhang B, Li Q (2016) Knowledge, Attitude and Practice on Immunization among Migrant Mothers: A Questionnaire Development and Field Application. Open Access 6. [28] The Gambia Bureau of Statistics (GBoS), Ministry of Health (MoH) [The Gambia], and ICF (2020) The Gambia Demographic and Health Survey 2019-20: Key Indicators Report. Banjul, The Gambia, and Rockville, Maryland, USA: The Gambia Bureau of Statistics, Ministry of Health, and ICF.

[29] Gambia Bureau of Statistics (2013) Gambia Demographic Health Survey 2013.

[30] Gambia Bureau of Statistics (2019) The Gambia Multiple Indicator Cluster Survey 2018, Survey Findings Report. Banjul, The Gambia. https://www.unicef.org/gambia/media/776/file/The \%20Gambia\%20Multiple\%20Indicator\%20Cluster \%20Survey\%202018.pdf/Accessed 16 Aug 2020. 